\title{
SYNTHESIS OF TI48AI2Cr2Nb INTERMETALLIC ALLOY POWDER FOR ADDITIVE MANUFACTURING BY MECHANICAL ALLOYING AND PLASMA SPHEROIDIZATION
}

\author{
Igor POLOZOV, Tagir MAKHMUTOV, Nikolay RAZUMOV, Artem KIM, Nikolay OZERSKOI, \\ Anatoliy POPOVICH
}

Peter the Great St, Petersburg Polytechnic University, Russian Federation, polozov ia@spbstu.ru https://doi.org/10.37904/metal.2019.934

\begin{abstract}
In this paper, Ti-48Al-2Cr-2Nb (at. \%) gamma-based alloy spherical powders were prepared by mechanical alloying of elemental powders and plasma spheroidization. Microstructural features and phase composition of the obtained powders were studied after different time of mechanical alloying in a planetary mill to investigate the alloy formation. After determining optimal milling parameters allowing to obtain powders with a fairly homogeneous microstructure and composition, the powders were treated in the flow of a thermal plasma to produce powder particles with a high degree of sphericity. The produced spherical powders were investigated using Scanning Electron Microscopy and X-Ray Diffraction. The study showed the feasibility of the suggested approach to fabricate spherical homogeneous powders of gamma-based intermetallic alloy for its application in Additive Manufacturing processes.
\end{abstract}

Keywords: Mechanical alloying, plasma spheroidization, titanium alloy, intermetallic, Ti48Al2Cr2Nb

\section{INTRODUCTION}

Intermetallic titanium aluminide $\mathrm{y}$-TiAl-based alloys are promising materials for manufacturing light-weight components of aerospace and automotive engines due to their high strength at elevated temperatures, low density and good oxidation and creep resistance [1,2]. Titanium aluminide alloys are considered to be candidates for replacing nickel-based superalloys, which are used for high-temperature parts in turbine engines [3]. However, TiAl-based alloys possess very low room temperature ductility and poor hot deformability and are prone to cracking during conventional processing methods. This makes manufacturing parts from TiAlbased alloys very cost and time-consuming. Existing conventional ways, e.g. extrusion or casting and isothermal forging, have extremely high costs and results in heterogeneous microstructure. Thus, processing TiAl-based alloys requires further development, e.g. application of powder metallurgy and Additive Manufacturing (AM) processing [4].

AM technologies, such as Selective Laser Melting (SLM) and Electron Beam Melting (EBM), allow the fabrication of complex-shaped components with high mechanical properties from powder feedstock [5]. While AM of titanium aluminide components is a promising way of producing complex parts, the availability of TiAlbased powders suitable for AM processes is still limited. Mechanical alloying (MA) allows obtaining powders with complex chemical composition, however the particles obtained by MA have irregular shape and usually require post-processing to be used in AM. Plasma spheroidization (PS) process can be used to give the powder particles spherical shape [6]. During plasma treatment at high temperatures, the particles are rapidly melted and then solidified resulting in a homogeneous microstructure and spherical shape [7].

Ti-48Al-2Cr-2Nb (at $\%)$ is one of the most widely use TiAl-based alloys. Addition of $\mathrm{Nb}$ to the alloy composition improves its high temperature resistance and addition of $\mathrm{Cr}$ increases its oxidation resistance [8].

In the current work, Ti-48Al-2Cr-2Nb intermetallic alloy powders were fabricated using elemental powders by MA followed by PS process. The microstructure, phase composition, and chemical composition of the produced powders after MA and PS were investigated. It was demonstrated that MA followed by PS can be used to fabricate spherical powders of TiAl-based alloy with homogeneous microstructure and composition. 


\section{MATERIALS AND METHODS}

The elemental powders of $\mathrm{Ti}, \mathrm{Al}, \mathrm{Cr}$, and $\mathrm{Nb}$ (with $99.9 \%$ purity) were mixed to obtain the composition of $\mathrm{Ti}$ $48 \mathrm{Al}-2 \mathrm{Cr}-2 \mathrm{Nb}$ (at\%) and then mechanically alloyed using a planetary mill Fritsch Pulverisette 4 in the argon atmosphere. The milling of the powders was stopped every $15 \mathrm{~min}$ for $15 \mathrm{~min}$ to prevent overheating of the powders with the change of rotating direction for the main disk and the bowls. The total time of the MA process was 10 hours. Steel balls of $12 \mathrm{~mm}$ diameter were used as the milling media with the ball-to-powder ratio of 15:1. The main disk rotation speed was $300 \mathrm{rpm}$ (clockwise direction) and the bowl rotation speed was 600 rpm (counterclockwise direction). After mechanical alloying, the obtained powders were sieved using a 125 $\mu \mathrm{m}$ sieve and then spheroidized in the Tekna TEK-15 plant with the inductively coupled plasma at $15 \mathrm{~kW}$ plasma torch power. The Ar-He gas was used as the plasma forming gas. The powder feeding rate was set to $15 \mathrm{~g} / \mathrm{min}$. TESCAN Mira 3 LMU scanning electron microscope (SEM) with secondary electrons (SE) and backscattered electrons (BSE) was utilized for the microstructural characterization of the powders. Energydispersive X-ray spectroscopy (EDS) option was used for local chemical analysis of the samples. The phase composition was analyzed with a Bruker D8 Advance X-ray diffraction (XRD) meter using Cu-Ka $(\lambda=0.15418$ $\mathrm{nm}$ ) irradiation.

\section{RESULTS AND DISCUSSION}

Figure 1 shows the BSE-SEM images of Ti-48Al-2Cr-2Nb powder particles' cross-sections after $10 \mathrm{~h}$ of MA. The powders obtained by MA have irregular particles' shape, which is typical for the powders fabricated by milling processes. From BSE-SEM images it can be seen that the particles feature inhomogeneous microstructure and distribution of chemical elements. There are white areas corresponding to $\mathrm{Nb}$ and $\mathrm{Cr}$ elements. In general, the particles after MA have layered type of microstructure typical for mechanically alloyed powders [9-11].
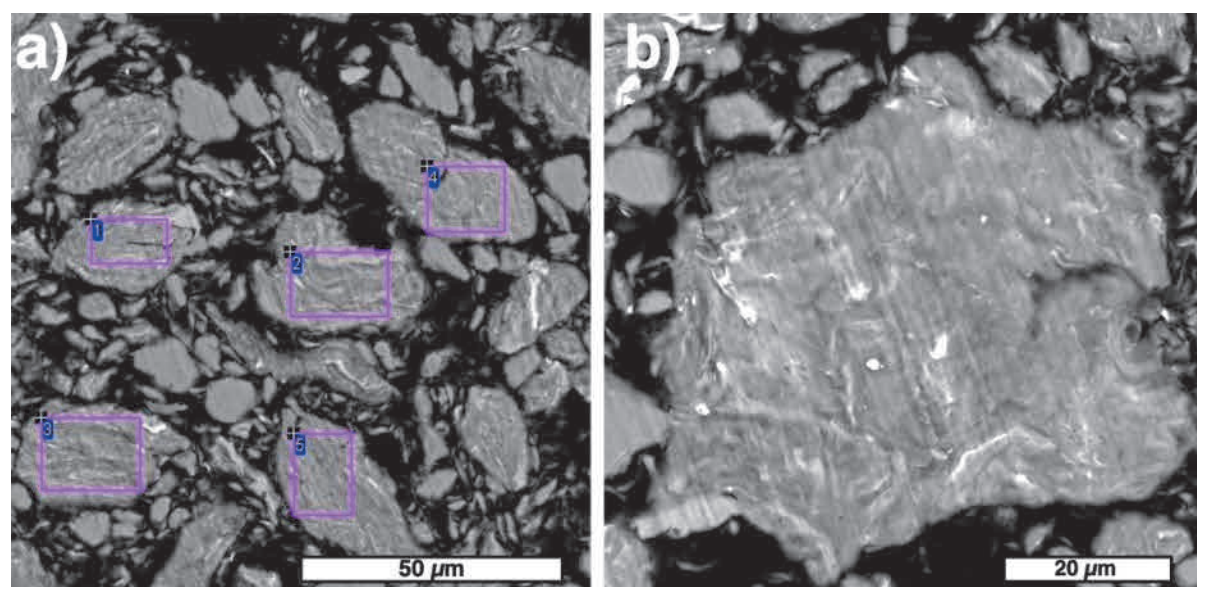

Figure $1 \mathrm{BSE}-\mathrm{SEM}$ images of Ti-48Al-2Cr-2Nb powders particles cross-sections after MA for $10 \mathrm{~h}$ at different magnification. The areas used for the EDS analysis are shown in a)

The EDS-maps (Figure 2) of the alloying elements in the powder particles obtained by MA show that Ti and $\mathrm{Al}$ are distributed relatively homogeneously, while $\mathrm{Nb}$ and $\mathrm{Cr}$ are characterized by areas with uneven distribution. The chemical composition of the powders according to the EDS results (Table 1) is in accordance with the initial composition of the elemental powder blend. However, there is a small Fe contamination of the powders after MA due to the use of steel grinding media. According to the XRD results (Figure 3), the powder after MA consists of hexagonal closed-packed titanium phase and aluminum. There are also small peaks corresponding to $\alpha_{2}-\mathrm{Ti}_{3} \mathrm{Al}$ phase. 
Table 1 The results of EDS measurements for the areas shown in Figure 1, a

\begin{tabular}{|c|c|c|c|c|c|}
\hline \multirow{2}{*}{ Area } & \multicolumn{5}{|c|}{ Element content (at\%) } \\
\cline { 2 - 6 } & $\mathrm{Ti}$ & $\mathrm{Al}$ & $\mathrm{Nb}$ & $\mathrm{Cr}$ & $\mathrm{Fe}$ \\
\hline 1 & 49.37 & 46.49 & 2.17 & 1.97 & - \\
\hline 2 & 51.21 & 45.30 & 1.87 & 1.62 & - \\
\hline 3 & 48.83 & 48.09 & 4.40 & 1.24 & 0.14 \\
\hline 4 & 48.82 & 47.55 & 2.04 & 1.45 & 0.08 \\
\hline 5 & 49.04 & 47.98 & 1.52 & 1.87 & 0.04 \\
\hline Mean & 49.46 & 47.06 & 1.89 & 1.53 & \\
\hline
\end{tabular}
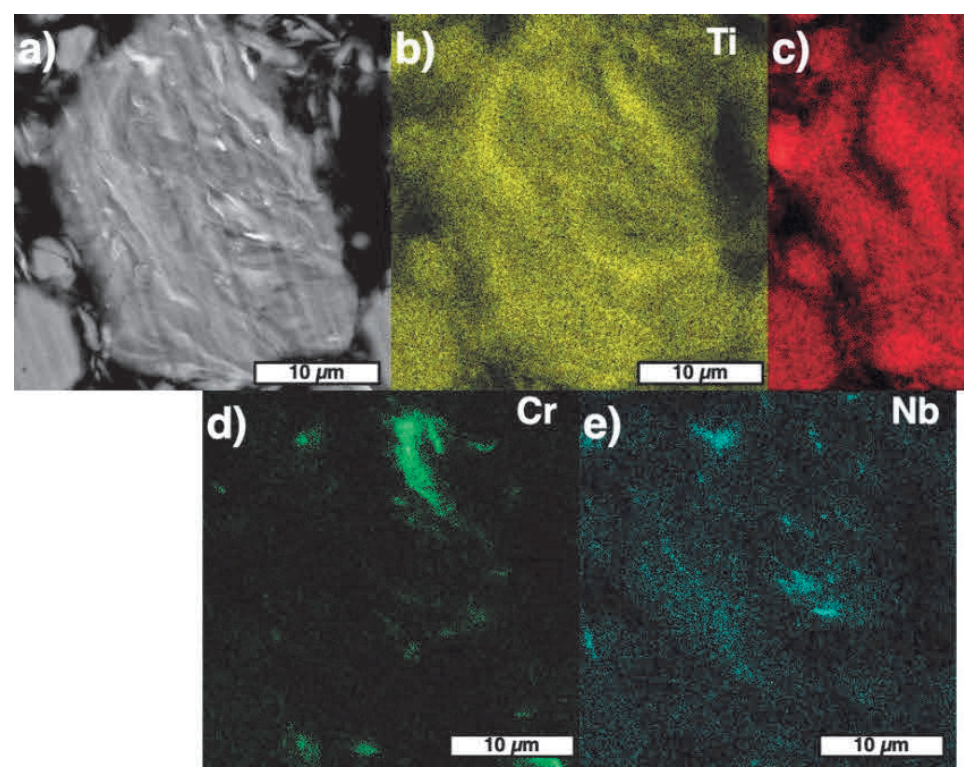

Figure 2 BSE-SEM image of the Ti-48AI-2Cr-2Nb particle's polished cross-section for the powder after MA and elements distribution

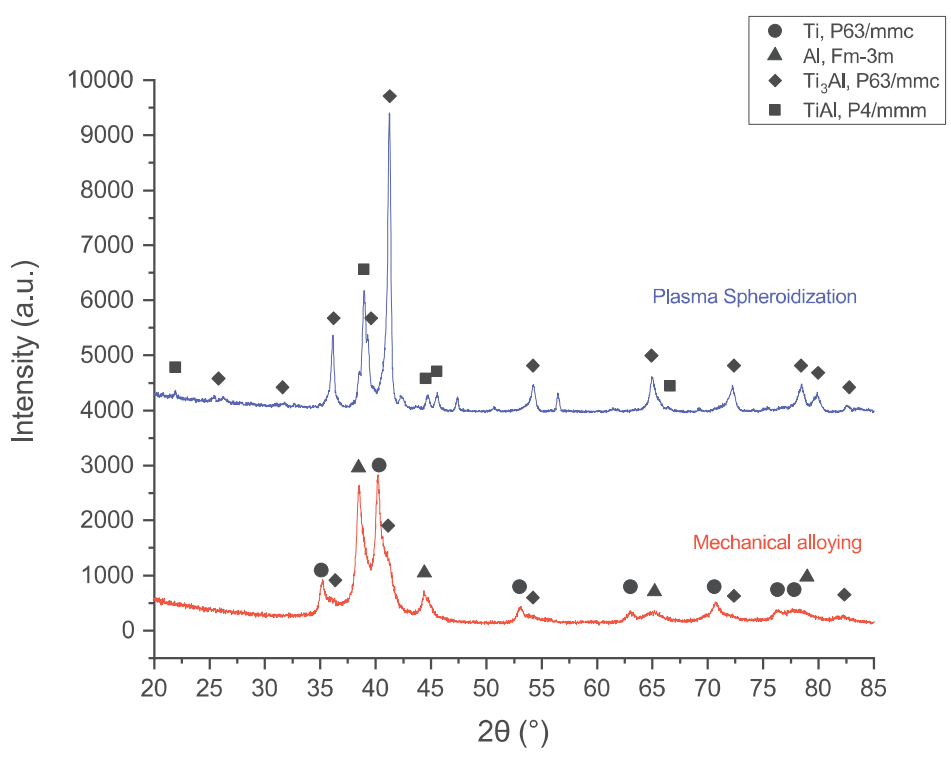

Figure 3 The XRD results of the powders after mechanical alloying and after plasma spheroidization processes 
After the treatment of the mechanically alloyed powders in the high-temperature plasma jet, the resulted particles are characterized by spherical shape (Figure 4). The XRD results show that after PS the powder consists of $\mathrm{Ti}_{3} \mathrm{Al}$-phase and TiAl-phase, while Al and Ti peaks disappeared. The main phase is $\mathrm{Ti}_{3} \mathrm{Al}$. According to the EDS-analysis, the fabricated powder has the following chemical composition: Ti-40.4Al-2.1 Cr-2.5Nb$0.3 \mathrm{Fe}$ (at\%). The Al content decreased by 7 at\%) after plasma spheroidization compared to the mechanical alloyed powder. This might be the result of partial evaporation of Al during plasma treatment. The reduced Al content might be not sufficient enough to form sufficient amount of TiAl-phase [12,13]. Thus, it is needed to increase $\mathrm{Al}$ content in the initial powder blend to obtain an alloy of the required composition. The cross-section of the fabricated powder particle shows dendritic microstructure [14] and consists mainly of supersaturated $\alpha_{2-}$ $\mathrm{Ti}_{3} \mathrm{Al}$ phase (Figure 5, a).

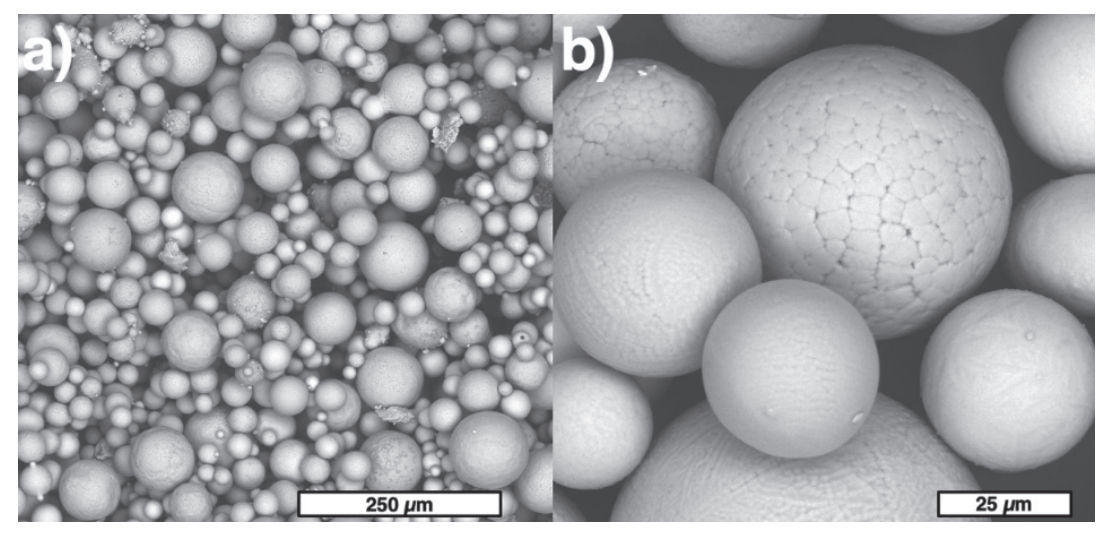

Figure 4 SEM-images of Ti-48Al-2Cr-2Nb powder particles after plasma spheroidization
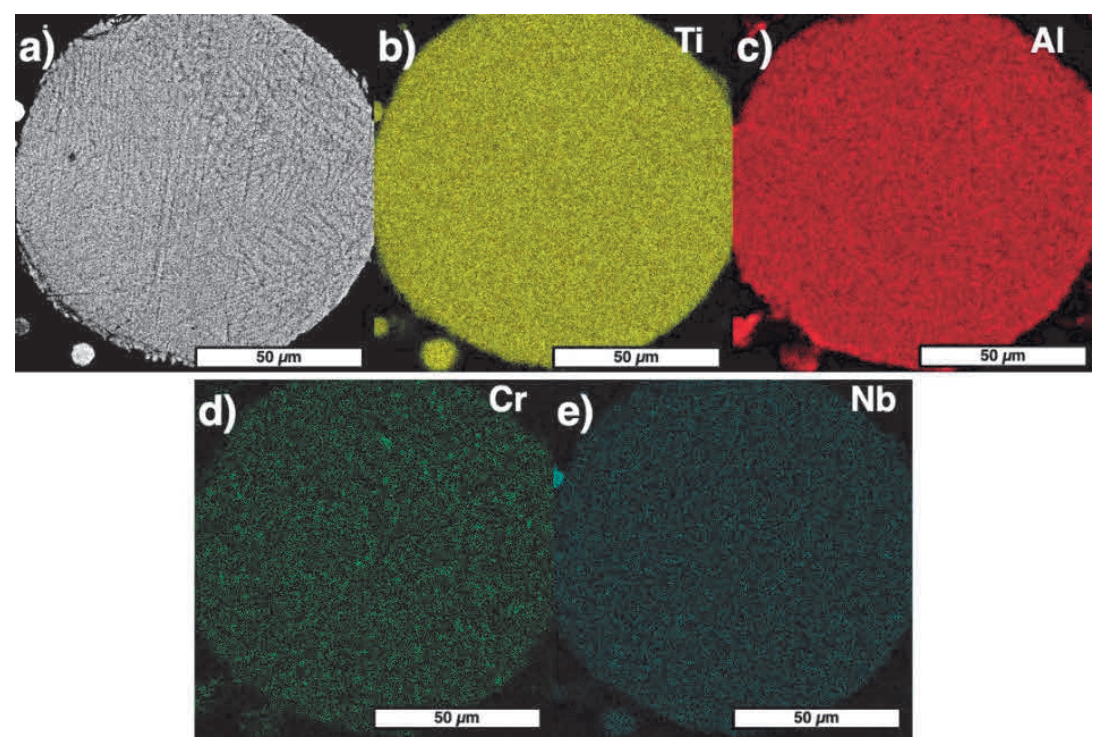

Figure 5 EDS-maps of Ti-48Al-2Cr-2Nb powders particle cross-sections after PS

\section{CONCLUSIONS}

In this study, titanium aluminide alloy spherical powder was fabricated by the combination of mechanical alloying and plasma spheroidization processes from Ti-48Al-2Cr-2Nb elemental powder blend.

The resultant chemical composition was Ti-40.4Al-2.1Cr-2.5Nb-0.3Fe (at\%), which is characterized by a decreased Al content due to its partial evaporation during plasma treatment and a small Fe contamination from steel grinding media. 
While the mechanical alloying resulted in powder particles with high degree of chemical inhomogeneity and irregular particle shape, the following plasma spheroidization process allowed obtaining highly spherical powder particles with homogeneous distribution of alloying elements. The produced powder consists of Ti3Al as the main phase and TiAl-phase and is characterized by dendritic structure.

The obtained powders can be used in AM processes, e.g. SLM, DMD, and EBM, after additional sieving depending on the requirements of the chosen AM technology.

\section{ACKNOWLEDGEMENTS}

This research was supported by Russian Science Foundation grant (project No 19-79-30002).

\section{REFERENCES}

[1] DOUBENSKAIA, M., DOMASHENKOV, A., SMUROV, I. and PETROVSKIY, P. Study of Selective Laser Melting of intermetallic TiAl powder using integral analysis. International Journal of Machine Tools and Manufacture. 2018. vol. 129, pp. 1-14.

[2] GUPTA, R., PANT, B. and SINHA, P. Theory and practice of $\mathrm{y}+\alpha 2$ Ti aluminide: A review. Transactions of the Indian Institute of Metals. 2014. vol. 67, no. 2, pp. 143-165.

[3] POLOZOV, I., SUFIIAROV, V., POPOVICH, A., MASAYLO, D. and GRIGORIEV, A. Synthesis of Ti-5Al, Ti-6Al$7 \mathrm{Nb}$, and Ti-22Al-25Nb alloys from elemental powders using powder-bed fusion additive manufacturing. Journal of Alloys and Compounds. 2018. vol. 763, pp. 436-445.

[4] LI, W., LIU, J., WEN, S., WEI, Q., YAN, C. and SHI, Y. Crystal orientation, crystallographic texture and phase evolution in the Ti-45Al-2Cr-5Nb alloy processed by selective laser melting. Materials Characterization. 2016. vol. 113, pp. 125-133.

[5] SCHWERDTFEGER, J. and KÖRNER, C. Selective electron beam melting of Ti-48Al-2Nb-2Cr: Microstructure and aluminum loss. Intermetallics. 2014. vol. 49, pp. 29-35.

[6] RAZUMOV, N., POPOVICH, A. and WANG, Q. Thermal Plasma Spheroidization of High-Nitrogen Stainless Steel Powder Alloys Synthesized by Mechanical Alloying. Metals and Materials International. 2018. vol. 24, no. 2, pp. 363-370.

[7] POPOVICH, A. et. al. Fabrication of the Nb-16Si Alloy Powder for Additive Technologies by Mechanical Alloying and Spheroidization in Electric-Arc Discharge Thermal Plasma. Russian Journal of Non-Ferrous Metals. 2018. vol. 59, no. 6, pp. 671-676.

[8] LEE, D., PARK, K. and NAKAMURA, M. Effects of $\mathrm{Cr}$ and $\mathrm{Nb}$ on the high temperature oxidation of TiAl. Metals and Materials International. 2002. vol. 8, no. 3, pp. 319-326.

[9] GONCHAROV, I. S. et al. Synthesis of Nb-based powder alloy by mechanical alloying and plasma spheroidization processes for additive manufacturing. Materials Letters. 2019. vol. 245, pp. 188-191.

[10] POPOVICH A.A. et al. Dissolution of alloying elements and phase formation in powder materials $\mathrm{Fe}-18 \mathrm{Cr}-8 \mathrm{Ni}-$ 12Mn-xN during mechanical alloying. Advanced Materials Letters. 2014. vol. 5, no. 12, pp. 683-687.

[11] POPOVICH A.A. et al. A study of the process of mechanical alloying of iron with austenite-forming elements. Metal Science and Heat Treatment. 2015. vol. 56, no. 9-10, pp. 570-576.

[12] BIAMINO, S. et al. Electron beam melting of Ti-48AI-2Cr-2Nb alloy: Microstructure and mechanical properties investigation. Intermetallics. 2011. vol. 19, no. 6, pp. 776-781.

[13] GUSSONE, J., HAGEDORN, Y., GHEREKHLOO, H., KASPEROVICH, G., MERZOUK, T. and HAUSMANN, J. Microstructure of $Y$-titanium aluminide processed by selective laser melting at elevated temperatures. Intermetallics. 2015. vol. 66, pp. 133-140.

[14] LIU, Y., HU, R., ZHANG, T., KOU, H., WANG, J., YANG, G. and LI, J. Dendritic growth and microstructure evolution with different cooling rates in Ti48AI2Cr2Nb alloy. Journal of Materials Engineering and Performance. 2016. vol. 25, no. 1, pp. 38-45. 